\title{
Perfil y compromisos del tutor como agente de transformación del estudiante
}

Juana Mora López / Oswaldo León Portillo

omenzaremos con esta reflexión: "Los jóvenes no se sienten vistos, no se sienten escuchados, se sienten abandonados emocionalmente" (Osorio, 2002).

El tutor, profesor que guía el proceso formativo y actividades académicas de los alumnos, debe distinguirse por tener ciertos rasgos y compromisos que lo diferencian de los profesores que se dedican completamente a su menester cotidiano dentro de las aulas; a continuación se mencionan algunos de éstos.

El tutor orienta, asesora y acompaña al alumno durante su proceso de enseñanza-aprendizaje para conducirlo hasta su formación integral (ANUIES, 2002: 96), lo que significa estimular en él la capacidad de hacerse responsable de su aprendizaje y de su formación; este profesor-tutor debe tener un amplio conocimiento de la filosofía educativa subyacente al ciclo y a la modalidad educativa y curricular del área disciplinar en la que se efectúe la práctica tutorial, pero su función esencial estriba en ayudar a los alumnos a resolver problemáticas cotidianas, pero sobre todo, orientarlos para que se descubran a sí mismos como seres capaces de responsabilizarse de su propia existencia.

Asimismo, es recomendable que sea un profesor o investigador que cuente con gran experiencia académica que le permita desarrollar eficiente y eficazmente la docencia o la investigación y que además estas actividades estén vinculadas con el área en la que se desenvuelven sus tutorados, para dirigirlos hacia su desarrollo integral; es decir, que de forma paralela a lo académico se desarrolle su personalidad a fin de que los futuros profesionales sean seres integrados.

También es importante que las dos partes (tutor-alumno) estén conscientes del significado de la tutoría, ya que este proceso conlleva un compromiso en el que el primero debe estar atento al desarrollo del estudiante, mientras que el segundo debe desempeñar un papel más activo como actor de su propio aprendizaje, todo en el marco de una relación más estrecha que la establecida en un aula durante un curso normal, ya que la tutoría no sólo consiste en estar frente al grupo, sino que las actividades van enfocadas al desarrollo humano y a fomentar potencialidades en los alumnos, a fin de que enfrenten la vida y los cambios de actitudes, para lo cual se deben analizar la propia personalidad, iden- 
tidad y las actitudes como orientadoras, para que de esta manera se pueda trabajar mejor con ellos. La práctica de la tutoría puede ejercerse en diferentes momentos y para distintos propósitos, ésta deberá incluir un conjunto de actividades denominadas genéricas que deberá cubrir todo profesor en su función de tutor.

El tutor deberá mantener una actitud ética, profesional y de empatía hacia los tutorados, mediante un esfuerzo permanente de comunicación, que le permita desarrollar las actitudes adecuadas para inspirar confianza y lograr la aceptación de los tutorados, manteniendo siempre un diálogo permanente en sentido positivo y la mayor tolerancia hacia sus reacciones, para lo cual debe apoyarse en su actuación siempre responsable y deberá atender sus compromisos con toda puntualidad y dentro de un marco de respeto y confidencialidad; deberá poseer habilidades y actitudes como la de ser creativo, crítico, observador y ordenado.

Asimismo, para conservar una adecuada relación con el alumno, el tutor estará dotado de habilidades para efectuar las entrevistas tanto de nivel personal, como grupal, debiendo estar entrenado para escuchar a los estudiantes y obtener la información que le sea útil para emprender las acciones que sean requeridas; esto es, que tenga un equilibrio entre la relación afectiva y cognoscitiva que le permitirá delimitar adecuadamente el proceso.

En la medida en que los programas tutoriales operen sistemáticamente, los jóvenes que se incorporen a ellos podrán ser ubicados en el

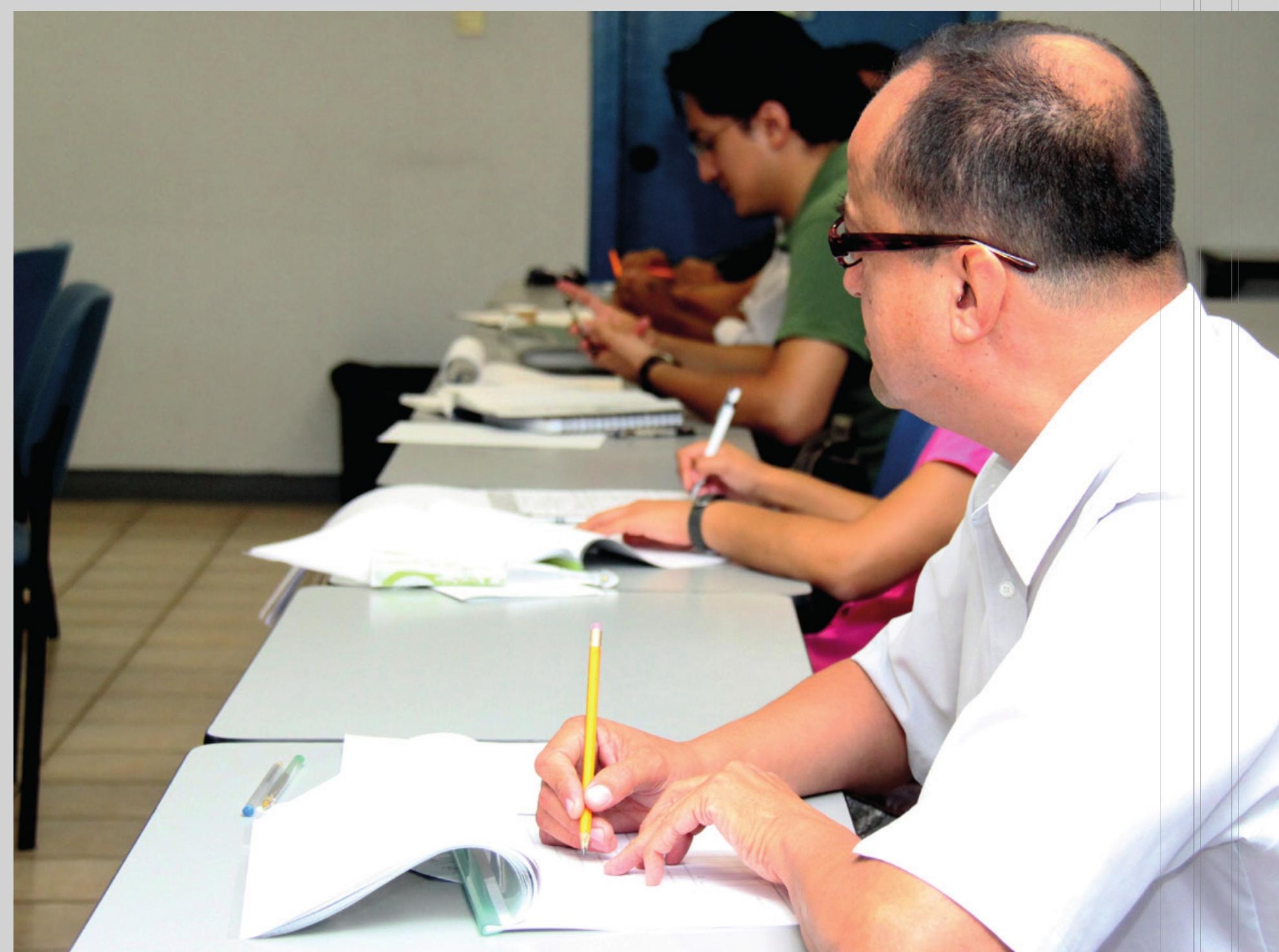


lugar correspondiente, es decir, con un tutor específico o en un servicio especializado, dependiendo de la situación particular. Con esto, el tutorado puede atender y resolver sus dudas, ampliar su perspectiva o profundizar en algún aspecto de su formación.

En concreto, entre los principales rasgos deseables para un tutor se encuentran:

- Poseer un equilibrio entre la relación afectiva y cognoscitiva, para delimitar el proceso.

- Tener capacidad y dominio del proceso.

- Tener capacidad para reconocer el esfuerzo en el trabajo realizado por el tutorado.

- Mantenerse actualizado en el campo respectivo.

- Contar con capacidad para propiciar un ambiente de trabajo que favorezca la empatía del binomio tutor-tutorado.

- Poseer experiencia docente y de investigación, con conocimiento del proceso de aprendizaje.

- Contar con habilidades y actitudes como: creatividad, capacidad para la planeación tanto del seguimiento del profesional, como del proceso de tutoría.

- Habilidades para la comunicación.

- Actitudes empáticas en su relación con el alumno.

\section{Fuentes de consulta}

Durón, T.L. y Oropeza, T.R. (1999). Actividades de estudio, análisis predictivo a partir de la interacción familiar y escolar de estudiantes de nivel superior. Documento de trabajo. México: Facultad de Psicología, UNAM.

ANUIES. (2002). Programas institucionales de tutoría. México: ANUIES.

Osorio Clark, R. (2002) Superación académica, una Escuela Nacional Preparatoria. Gaceta ENP. México: UNAM. 